\title{
INTRODUCTION
}

\section{Reciprocity and the Normativity of Legal Orders ${ }^{*}$}

\author{
Hans Lindahl \& Bart van Klink
}

\section{Theme}

This special issue offers a selection of the lectures delivered by key-note speakers during the Summer School organized by the editors in August, 2013, at the behest of the Section of Ethics \& Practical Philosophy of the Dutch Research School of Philosophy (OZSW). Every year the Section of Ethics \& Practical Philosophy hosts a Summer School for PhD candidates of the Netherlands and abroad on themes within the compass of this broad field of philosophical enquiry. The Summer School of 2013 was tailored to PhD candidates in the fields of legal philosophy, political philosophy and ethics. While the focus was on reciprocity in legal orders, the conceptual, normative and field-specific issues were presented in a way that was accessible to doctoral candidates in practical philosophy who have no prior law degree. An important aim of the summer school was, in fact, to foster dialogue between legal philosophers on the one hand, and political philosophers and ethicists, on the other. The decision to select reciprocity as the focus of the Summer School was driven by the central role it plays in modern accounts of the normativity of normative orders in general, and legal order in particular.

Indeed, in different ways and with different accents, contemporary philosophers such as Rawls, Nagel, Habermas, Taylor, Gadamer and Ricoeur all posit the principle of reciprocity as constitutive for the normativity of the law, no less than for politics and ethics. In fact, it is perhaps not exaggerated to assert that these authors, and their great predecessors going from Hobbes to Hegel, view reciprocity as the common root of the normativity of law, politics, and ethics. It is significant, in this respect, that both communitarian and cosmopolitan approaches to the normativity of normative orders grant pride of place to the notion of reciprocity. No less significantly, reciprocity has also become the object of considerable interest in analytically oriented theories of collective intentionality and action, where it plays a key role in accounting for joint action and, as a consequence, for political and legal obligation (e.g., Gilbert, Bratman, Pettit). Recognition of the constitutive normative significance of reciprocity is not limited, however, to philosophers. A wide range of anthropologists and sociologists, including Marcel Mauss and Claude Lévi-Strauss, argue that reciprocity is in fact the structuring principle of social orders in general, which explains a disparate range of activities including the gift, economic transactions and revenge. Acknowledging the broader disciplinary scope of the theme, the special issue 
includes a contribution that offers the philosophically oriented reader a sense of how the social sciences approach reciprocity.

Despite the ubiquity of reciprocity, there is considerable debate about what precisely reciprocity means, and how it is related to associated notions, such as symmetry and mutuality. These and related conceptual questions spill over into the properly normative debate about reciprocity. Additionally, there are field-specific issues pertaining to reciprocity, meaning by such domains of law in which reciprocity is a recurrent conceptual and normative problem: private law (e.g., contract and private self-regulation); public law (e.g., equality and the principle of non-discrimination, the distinction between citizen and denizen with regard to political rights, tolerance); environmental law (e.g., intergenerational obligations); criminal law (e.g., punishment). The contributions to this special issue span the entire gamut of conceptual, normative and field-specific dimensions of the topic.

With a view to providing a certain focus to the different contributions to the Summer School the editors invited the key-note speakers to take John Rawls' 'Justice as Reciprocity', published in his Collected Papers, as the background text (and no more than that!) for their own reflections. While not necessarily the decisive contribution to the topic, this paper does offer a perspicuous and accessible analysis of the notion in a way that explicitly posits reciprocity as constitutive of the normativity of legal and political orders. To cite the key passage of the paper,

'[T] authority over one another and who are engaging in or who find themselves participating in a joint activity, are among themselves settling upon or acknowledging the rules which define it and which determine their respective shares in its benefits and burdens. ${ }^{1}$

This formulation suggests that reciprocity comes to the fore as a normative principle when individuals seek to reach agreement about the terms of joint action, either when entering into it or when renegotiating its terms. As Rawls further explains it, joint action 'will strike the parties as conforming to the notion of reciprocity if none feels that, by participating in it, her or any of the others are taken advantage of or forced to give in to claims which they do not accept as legitimate.' ${ }^{2}$ Obligations, legal obligations in particular, derive their binding character from joint action that meets the criterion of reciprocity: 'their engaging in it gives rise to a prima facie duty (and a corresponding prima facie right) of the parties to each other to act in accordance with the practice when it falls upon them to comply.'3 By settling their differences in accordance with the principle of reciprocity, and discharging their obligations under joint action that satisfies the principle,

1 John Rawls, 'Justice as Reciprocity', in John Rawls, Collected Papers, ed. Samuel Freedman (Cambridge, MA: Harvard University Press, 1999), 208.

2 Ibid.

3 Ibid., 209. 
participants engage in mutual recognition; they 'exhibit their recognition of each other as persons with similar interests and capacities.' ${ }^{4}$ Joint action that realises mutual recognition vouches, by Rawls' lights, for a 'well-ordered', i.e., a just, society.

To repeat an earlier caveat, Rawls' account of reciprocity is by no means the only version thereof. But it does justify the claim that reciprocity is crucial to a number of questions that go to the heart of the normativity of legal orders, and which the editors requested the key-note speakers and participant $\mathrm{PhD}$ candidates to reflect on in the course of the Summer School: What sense are we to make of equality among citizens in societies marked by deep-seated differences, cultural and otherwise? Does political equality between citizens presuppose a more fundamental moral equality between human beings, such that, for example, decisions about the entry of immigrants or asylum seekers to a polity should be based on decisions that can count on the consent of both citizens and those who seek entry? Whence do legal obligations derive their binding character when they can no longer be viewed as the articulation of a substantive human essence? Why is the notion of a (social) contract paradigmatic for the conceptions of legitimacy prevalent in modernity?

\section{Contributions}

The contributions to this special issue can be divided roughly into two categories: while some authors argue that reciprocity is a central and valuable principle which may be used to understand, justify or criticize relations and interactions in law, politics or society at large (Dyzenhaus, Kostakopoulou, Taekema and Pessers), other authors call attention to the negative social effects of philosophical conceptions of reciprocity (Westerman and to a certain extent Komter) and deny that reciprocity is or should be a fundamental principle of law (Westerman).

To begin with, David Dyzenhaus seeks to demonstrate that reciprocity can be seen as the foundational principle of normative, political and legal order in Hobbes's social contract theory. Hobbes is commonly understood as demanding an almost unconditional obligation of citizens to follow the commands of the sovereign. Against this authoritarian reading, Dyzenhaus offers a liberal interpretation of Hobbes's social contract according to which it establishes three kinds of reciprocal relations. First, in the state of nature individuals agree with each other to create a sovereign who is authorized to issue binding commands. This pact, based on a horizontal relationship between individuals, gives rise to a second kind of reciprocity: in return for their obedience, citizens are protected from the dangers that characterize the state of nature. In addition to this vertical relation, a third, horizontal relation of reciprocity is established among individuals who recognize each other as free and equal individuals and who are permitted by the law to pursue their own conception of the good. Although the sovereign has a monop- 
oly on legislative power, he is under a duty to respect the basic freedom and equality of the people. Moreover, the subordinate judges have to interpret the civil law in accordance with these laws of nature.

Dora Kostakopoulou agrees that liberal political theory is based on the belief that individuals, irrespective of their class, caste, race, gender, nationality and so on, deserve equal respect and concern. In practise though, liberal democracies offer the right to participate in society on equal and fair terms and to profit from its goods on an equal basis only to those people who are recognized as citizens belonging to a particular nation-state. Migrants, for instance, are excluded from the benefits of reciprocity: they are expected to contribute to society by working, paying taxes and respecting the law, but they are not granted full social and political rights. They are accepted as full-fledged members of society that enjoy the rights of citizenship only after an exhausting and degrading process of integration and naturalization. Objecting to this national conception of reciprocity, Kostakopoulou pleads for a more comprehensive understanding thereof, according to which people should acquire membership (and all the rights it entails), not so much on the basis of their nationality, but rather because of their valuable contribution to a particular community. Diversity and pluralism should be welcomed in society and not suppressed. 'Community is a dull affair without disagreements, different beliefs, diverse imaginations and conflicts.'

Sanne Taekema investigates how reciprocal relations figure in two areas of private law: contract and tort. In her view, law has an interactional character in these legal domains because it depends on moral norms implicit in social practices rather than on formal legal rules. Law cannot be understood without taking account of people's everyday reciprocal expectancies, or so she claims. When judges are dealing with cases of contract and tort, they do not apply a legal rule, taken from a statute or a prior decision; instead, they assess what people in this particular case could reasonably expect from each other. Key norms in private law are often general clauses, such as the duty of 'due care', which have to be interpreted in light of the implicit moral and social norms contained in interactional law. However, interactional law based on reciprocity does not replace enacted law; it provides it with content and contributes to its normative force.

Dorien Pessers considers reciprocity to be a fundamental moral force in society. As Marcel Mauss has shown in his classic study of the gift, as soon as someone receives something from someone else, s/he feels an obligation to give in return. In order to explain the role that reciprocity plays in legal orders one has to make, according to Pessers, a distinction between two moralities of human interaction: reciprocity as a social morality of duty and mutuality as a contractual morality of rights. In its purest form, reciprocity does not generate legal rights and duties. 'The mechanism of reciprocity has its own and silent laws and rules.' Reciprocity creates social obligations among people who usually know each other well (e.g., friends or family members) and who trust each other. Mutuality, on the other hand, is based on the morality of contract law. It is a relationship among strangers who are not sure whether they can trust each other. The contracting parties 
spell out in detail what they have to give each other at what exact time. A contract generates rights and duties that are legally enforceable. In our society, where citizens are strangers to each other, mutuality is the dominant morality. However, she argues, in high trust societies reciprocal relations can be developed. For instance, in welfare states citizens are willing to pay tax and social charges, trusting that one day when they are in need their gift will be returned. Both kinds of morality can fall into decline and their negative effects have to be compensated for. In order to redress social injustice, norms of reciprocity have been implemented in mutuality based contract law by appealing to the moral responsibility of the parties involved (a process that is also described in Taekema's article). Pessers concludes that, once reciprocity and mutuality are balanced in a proper way, they together constitute the normative foundation of our legal order.

Building on empirical, sociological and anthropological insights, Komter and Westerman take a more critical stance towards philosophical accounts of reciprocity. Aafke Komter distinguishes a 'real-life' concept of reciprocity from the 'idealized' notion of reciprocity put forward by Rawls and others. Whereas reciprocity as an ideal notion presupposes equality, freedom and rationality, in daily life it often appears to bring about the exact opposite by giving rise to norms of obligation and triggering feelings of moral indebtedness. Reciprocity is an essential social mechanism, because it contributes to social stability and survival. At the same time, it also creates asymmetrical relations among people. Due to power inequality, the right to receive benefits is usually granted to those in power, whereas the powerless are under a duty to provide benefits. Moreover, reciprocity may act as principle of exclusion: those who give much will receive much, while those who are not able or not willing to give much will also receive little in return. Komter does not reject the idealized notion of reciprocity altogether, but assigns it to a specific sphere of social life. When developing principles of justice in the formal context of social, legal and political institutions, it may be helpful to take a detached philosophical point of view which abstracts from empirical varieties of reciprocity and possible negative social effects. However, in the less formalized context of day-to-day interactions, the real-life perspective seems to be more appropriate.

Komter seems to offer a 'theory of two truths': a common-sense truth suited for daily life and a 'higher', philosophical and idealistic truth applicable to formal institutions in juridical and political life. Pauline Westerman takes a more radical step by denying that there is any truth in the philosophically idealized notion of reciprocity as a principle to justify law. Reciprocity as an ideal notion can refer either to a fair exchange between two more or less equal parties or to the general communicative requirement that one has to be able on principle to take over the role of the other. According to Westerman, both ideals are empirically underinformed. Taking seriously a wealth of sociological and anthropological insights into the nature of reciprocity seriously demands acknowledging that reciprocal relations are often not very stable. The logic of exchange of gifts and benefits results in unequal relations and exclusion. Therefore, Westerman concludes, reci- 
procity cannot serve as a normative foundation of law. It is the other way around: law should redress the negative social effects of reciprocity and restore the balance that reciprocity has disrupted. In her view law-makers should turn away from moral philosophy and to social science, instead: 'In order to establish a body of law which is well-equipped to do this successfully, sociological insights in the nature and mechanisms of reciprocity seem to be more appropriate and helpful than moral philosophers.'

\section{Normative theory and empirical knowledge}

In this special issue, various normative and empirical perspectives on reciprocity are connected and confronted with each other. Methodologically speaking, this raises very interesting questions on the relation between factual and normative claims, the comparability of concepts used in different disciplines and the translatability or transferability of concepts from one discipline to the other. To what extent can or should a normative philosophical theory be in accordance with facts established in an empirical discipline? Obviously, normative theory cannot construct principles that fly entirely in the face of empirical findings, even while acknowledging that empirical findings are theory-laden and always involve, to a lesser or greater extent, a range of normative presuppositions. But it would be a mistake to simply write off a certain critical distance of normative theory with respect to empirical knowledge. In this vein, some imperfections of social reality - such as inequality among people - may deliberately be ignored, for the time being, in order to find principles that may guide a just legal and political order (as Rawls did), exactly with the aim of criticizing and correcting these imperfections in real life. Some idealization seems inevitable when a philosopher develops an ideal theory. But how far may this idealization get out of step with reality? If it is true, as Komter and Westerman claim, that reciprocity by necessity generates unstable relations of indebtedness, inequality and suppression among people, how can it serve as a suitable principle for the ordering of a just society?

Conversely, from a philosophical point of view the question may be raised how an empirical approach construes and justifies its theoretical and normative framework. Where does it get its concepts from? Not necessarily from social reality itself, in which a concept such as reciprocity may not be used and not even be known. Moreover, how do these theoretical notions relate to the vocabulary used in normative theory? It is not evident that the various authors are speaking about the same phenomenon when they use the concept of reciprocity within either an empirical or a philosophical context. Is a 'real-life' concept of reciprocity comparable and compatible with an idealized notion? Does a philosophical concept of reciprocity need to take into account all the fine distinctions that an empirical approach to reciprocity as a social phenomenon seems to require (such as between asymmetrical, negative, direct and indirect reciprocity)? Furthermore, it may be asked how an empirical approach can justify its normative claims. Komter acknowledges that reciprocity may be a valuable principle for social, legal and 
political institutions, but why so? Westerman denies that reciprocity is a good foundation for a legal order, but argues instead that law should correct the deficiencies of reciprocity as a social principle; again, why is this the case? What exactly is the normative ground of these claims? Is it possible to make these claims without some normative philosophical concept of reciprocity? Finally, does one have to reject a principle tout court if it in some instances, operating on its own, produces undesirable results? Perhaps additional principles are needed, such as equality, fairness or mutuality (as Pessers claims), in order to strike the right balance in reciprocal relations - however, that is something an empirical approach cannot determine.

So, the contributions to this special issue evoke a debate on the nature of reciprocity and its relevance for normative, legal, political and social order, as well as on the best way to investigate reciprocity, empirically and/or normatively. We hope that these challenges of reciprocity and challenges to reciprocity will be reciprocated, as science requires, by critical readings and critical responses. 